\title{
Factors associated with a low adherence to a Mediterranean diet pattern in healthy Spanish women before pregnancy
}

\author{
Rocío Olmedo-Requena ${ }^{1,2}$, Julia Gómez Fernández ${ }^{3}$, Carmen Amezcua Prieto', \\ Juan Mozas Moreno ${ }^{4}$, Aurora Bueno-Cavanillas ${ }^{1,2,5}$ and José J Jiménez-Moleón ${ }^{1,2, *}$ \\ 'Department of Preventive Medicine and Public Health, University of Granada, Avenida de Madrid 11, 18071 \\ Granada, Spain: ${ }^{2}$ CIBER de Epidemiología y Salud Pública (CIBERESP), Spain: ${ }^{3}$ Gynecology and Obstetrics \\ Service, Jaen Hospital Complex, Jaén, Spain: ${ }^{4}$ Obstetrics and Gynecology Service, Virgen de las Nieves \\ University Hospital, Granada, Spain: ${ }^{5}$ Preventive Medicine Service, San Cecilio University Hospital, \\ Granada, Spain
}

Submitted 7 June 2012: Final revision received 20 0ctober 2012: Accepted 5 February 2013: First published online 18 March 2013

\begin{abstract}
Objective: To analyse the factors associated with the level of adherence to a Mediterranean dietary pattern in healthy Spanish women before pregnancy. Design: A prospective series of 1175 women. An FFQ validated in Spanish populations served to collect dietary data. The Mediterranean Diet Adherence Index was used to assess the level of adherence to a Mediterranean diet pattern. Polytomic regression was performed to identify the associated factors.

Setting: Catchment area of Virgen de las Nieves University Hospital, Andalusia, Spain.

Subjects: The women were invited to participate in the study at the 20th-22nd gestational week. The selection criteria were: Spanish nationality, 18 years of age or older, singleton pregnancy and absence of health problems that required modifying the diet or physical activity.

Results: An inverse relationship was found between women's age and level of adherence to a Mediterranean diet pattern, with a clear dose-response association: a younger age entailed worse adherence $(P<0 \cdot 001)$. The habit of smoking and sedentary lifestyle had a positive relationship with low adherence, giving $\mathrm{OR}=5 \cdot 36(95 \% 1 \cdot 91,15 \cdot 07)$ for women who smoked $>20$ cigarettes $/ \mathrm{d}$ and $\mathrm{OR}=2 \cdot 07(95 \% \mathrm{CI} 1 \cdot 34,3 \cdot 17)$ for sedentary women. Higher age, higher educational level, and higher social class of the women were associated with a higher level of adherence to the Mediterranean diet $(P<0 \cdot 001)$.

Conclusions: In our sample population, younger age, lower social class, primary educational level and elements of an unhealthy lifestyle such as smoking and lack of exercise were associated with low adherence to a Mediterranean diet.
\end{abstract}

Keywords

Mediterranean diet Childbearing women Healthy lifestyle
The Mediterranean diet is the typical dietary pattern of the Mediterranean countries. The first reference to this type of diet as such was in 1938, when Leland Allbaugh studied the inhabitants of the island of Crete and their eating habits. Later, in 1957, Ancel Keys developed the concept of the Mediterranean diet in the Seven Countries Study ${ }^{(1,2)}$. In that study, Keys et al. analysed the relationship between deaths from CHD and serum cholesterol in fifteen populations in seven countries, at the individual level and for the population as a whole. The Mediterranean diet is characterized by daily consumption of fruit, vegetables, wholegrain cereals and pulses; a high consumption of MUFA, primarily from olive oil; moderate consumption of fresh fish and dairy products (especially cheese and low-fat dairy products), poultry and eggs; a moderate daily consumption of alcohol, normally red wine with meals; and a low consumption in frequency and quantity of red meats and sausages ${ }^{(3-6)}$. The basic characteristics of this dietary pattern are common to all countries of the Mediterranean basin, despite certain variations.

Diet is known to be a major determinant of an individual's health status and inadequate eating habits (excessive, deficient or both) are associated with numerous pathologies that may have high mortality rates. At present, a number of benefits of the Mediterranean diet are acknowledged, specifically with regard to mortality from all causes ${ }^{(7,8)}$, CVD $^{(9-12)}$, type 2 diabetes mellitus $^{(13-15)}$ and obesity ${ }^{(4,6)}$, as well as some types of cancer including breast, endometrial, ovary and prostate cancer ${ }^{(16-19)}$, according to the results of many epidemiological studies and clinical trials. In addition, there are known benefits of the Mediterranean diet on pregnancy outcomes ${ }^{(20-22)}$. 
Nevertheless, this healthy dietary pattern is on the wane in Southern European countries. In the population of Spain, a decrease in adherence to the Mediterranean diet was corroborated using FAO food balance sheets for two periods, 1961-1965 and 2000-2003 ${ }^{(23)}$. This decrease is associated with a trend towards more sedentary or unhealthy lifestyles ${ }^{(6,23,24)}$. The decrease in adherence to the Mediterranean diet affects all age groups. One particularly important group is women of fertile age: first because of the impact of diet on the health of the woman, the pregnancy and the newborn; and second because women of this age are more prone to accept advice regarding their health ${ }^{(25-28)}$. This indeed points to a need to promote the Mediterranean diet among pregnant women and women of childbearing age. We surmise that identifying the factors associated with decreasing adherence to the Mediterranean diet would be key in developing programmes aimed at improving the level of adherence. No previous studies look at this particular aspect of healthy diet promotion. The aim of our study was therefore to analyse the factors associated with low adherence to a Mediterranean dietary pattern in healthy Spanish women before pregnancy.

\section{Experimental methods}

We conducted a prospective series of 1175 pregnant women in the catchment area of Virgen de las Nieves University Hospital of Granada (southern Spain). This regional hospital has three units: a General Hospital, a Hospital of Orthopaedic Surgery and Rehabilitation, and a Maternity Hospital; it provides coverage for the northern half of the province of Granada, Spain, with a population of 400000 and approximately 4000 births per year ${ }^{(29)}$.

The reference population consisted of all the healthy pregnant women living in this area and attending their 20th gestational week visit at the hospital during the recruitment period, from June 2004 to March 2007. According to the Andalusian Maternal and Neonatal Health Programme, apart from routine prenatal visits to the primary health-care centre, all pregnant women should attend a prenatal visit at the hospital around the 20th week of gestation for ultrasound examination. The study was conducted according to the guidelines laid down in the Declaration of Helsinki. Ethical approval was given to the study by the Ethics Committee of the University of Granada and Virgen de las Nieves Hospital. All women signed a written consent form before participating.

The selection criteria were as follows: singleton pregnancy, Spanish nationality, 18 years of age or older, absence of complicated pregnancies that required rest, and absence of metabolic, chronic or acute diseases that might limit daily activities. From the original set of women, one in every five was systematically recruited, selected according to the order of their hospital visit for the ultrasound examination at week 20-22 of gestation, with a mean of 21.0 (SD 3.7) weeks. During the recruitment period a total of 1222 women were selected from the reference population, although finally 1175 women fulfilled inclusion criteria and chose to take part in the study.

All the pregnant women were contacted by two previously trained interviewers just before the ultrasound examination. After agreeing to participate, each woman was interviewed face to face and a structured questionnaire was used to collect the information. A pilot sample of fifty women (not included in the present study) had previously been interviewed during a 2-month period to train the interviewers and check the consistency of the information gathered.

Information about sociodemographic, obstetric and lifestyle variables (tobacco, diet, alcohol and physical activity) was collected. The information on diet was gathered by means of an FFQ that had previously been translated, adapted and validated in a sample of 147 Spanish women aged 18-64 years ${ }^{(30)}$ and used in other studies in Spanish populations ${ }^{(31-34)}$. Participants were asked about the frequency and amount of intake of 118 types of food during the year previous to the pregnancy; the frequency of intake of these foods (with reference to a table of equivalent portions) was then recorded as daily, weekly or monthly.

Dietary pattern was assessed using the Mediterranean Diet Adherence Index developed by Serra-Majem et $a l^{(35)}$. This index is based on Spanish dietary guidelines and includes the usual intake of fifteen food groups: (i) Fresh fruit and fruit juice; (ii) Vegetables, tomato juice (gazpacho) and lettuce; (iii) Nuts and olives; (iv) Fish and pulses; (v) Yoghurts and cheeses; (vi) Wine and cava; (vii) Olive oil; (viii) Other oils; (ix) Bread, pasta and rice; (x) Wholegrain bread, pasta and rice; (xi) Meats, sausages and cold cuts; (xii) Potatoes; (xiii) Baked goods, cookies and sweets; (xiv) Salty snacks; and (xv) Alcoholic beverage consumption and frequency. Dietary variables were energy-adjusted before scoring by using the residuals from the regression of nutrients $v$. total energy intake (residual method) ${ }^{(36)}$.

We calculated the mean intake per day for each food group. Ratings were assigned to each based on the tertile of consumption and on whether or not the group is considered characteristic of the Mediterranean diet. For the healthy food groups (items 1 to 7, 9, 10 and 12 of the index), the woman received 1 point if she was in tertile 1 (lowest consumption), 2 points for tertile 2 and 3 points for tertile 3 (highest consumption). The computation was inversed for non-healthy food groups. Accordingly, the maximum score was 45 points (the most beneficial effects). Recording by tertiles allowed us to distinguish between women with a low, mid or high level of adherence to the Mediterranean diet. 
Our physical activity questionnaire was based on the Paffenberger Physical Activity Questionnaire ${ }^{(37)}$, which identifies the type, frequency and duration of different physical activities during leisure time, household tasks and care-giving, occupational and other activities (watching television, using a computer, driving, sleeping, going out with family and friends). We focused on leisure-time physical activity before pregnancy, assigning each kind of activity reported in the questionnaire a specific intensity score (metabolic equivalent of task; MET) based on Ainsworth's Compendium of Physical Activity. This information was converted into MET hours per day $\left(\right.$ MET-h/d) scores $^{(38)}$, divided into tertiles, and graded as minimal physical activity (tertile 1), medium physical activity (tertile 2) and maximum physical activity (tertile 3 ).

Current smokers were defined as those who smoked at least one cigarette daily, and the following categories were established for smoking habit: 0 cigarette/d, $\leq 20$ cigarettes/ $\mathrm{d}$ and $>20$ cigarettes $/ \mathrm{d}$. The educational level of the woman was registered as: primary academic level (8 years or less of basic education); secondary ( 4 years of secondary education); and university, undergraduate or graduate studies. Social class was classified based on the classification of the Working Group of the Spanish Society of Epidemiology from lowest (V) to highest (I): Class I (managerial and senior technical staff and freelance professionals); II (intermediate occupations and managers in commerce); III (skilled non-manual workers); IV (skilled manual workers); and V (unskilled manual workers) ${ }^{(39)}$. We collected information about occupation for both members of the couples and the social class category was determined by the highest class declared by either one of them. Previous pregnancies and miscarriages were also registered. BMI was calculated as weight (in kilograms) just before pregnancy divided by the square of height (in metres). Both weight and height were obtained from medical records of the women if possible, and self-reported if not. Cut-offs set by the WHO were used to determine overweight and obese women $^{(40)}$. Women with $\mathrm{BMI} \geq 30 \mathrm{~kg} / \mathrm{m}^{2}$ were classified as obese, and those with BMI from $\geq 25 \mathrm{~kg} / \mathrm{m}^{2}$ to $<30 \mathrm{~kg} / \mathrm{m}^{2}$ as overweight.

We calculated the mean and standard deviation for the quantitative variables of study. The absolute and relative frequency distributions were estimated for qualitative variables. ANOVA was performed to compare the mean energy and Mediterranean Diet Adherence Index score for each of the independent variables. Significance was set at $P<0 \cdot 05$. Crude and adjusted odds ratios and $95 \%$ confidence intervals were computed by models of polytomic regression to identify factors associated with low or mid level of adherence to a Mediterranean diet. Epidemiological and statistical criteria were used to model variable selection. High level of adherence to the Mediterranean diet was taken as the reference category for dependent variables. Analyses were performed using the statistical software package SPSS version 15 .

\section{Results}

During the period of recruitment, the 1222 women who met the selection criteria were invited to participate in the study. Of these women, thirteen chose not to participate $(1.06 \%)$, and nineteen did not complete the interview face to face, or by telephone at a later attempt (1.55\%). Some basic information was lacking in fifteen cases. Therefore, $1175(96 \cdot 2 \%)$ of the eligible women were included in the analysis.

Table 1 shows the Mediterranean Diet Adherence Index score and its distribution in terms of demographic, social and obstetric variables. The lowest and highest values recorded were 20 and 36 points, respectively ( 45 points being the maximum score possible), and the mean obtained was $28 \cdot 2$ (SD 3.2) points. Figure 1 shows the mean number of daily servings for each of the fifteen food groups established. It is seen that the healthy food groups predominating are vegetables, bread and fruit, although the mean number of daily servings did not meet dietary recommendations. The most frequent unhealthy food groups were meat and sweets. The main source of dietary fat was olive oil, with very low use of other fats (sunflower oil, butter). Moderate consumption of red wine with meals was a relevant finding.

Table 2 shows the main variables considered depending on the level of Mediterranean diet adherence divided into tertiles: low, middle and high adherence. Greater age, higher educational level and higher social class of the woman were associated with a higher level of adherence to the Mediterranean diet $(P<0 \cdot 001)$. On the contrary, sedentary lifestyle and smoking were associated with a lower level of adherence $(P<0 \cdot 001)$. This relationship remained after adjusting for potential confounding factors (Table 3 ).

A direct relationship was found between age and degree of adherence to the Mediterranean diet; it was observed that as age increased, pregnant females' adherence increased, and in turn, the younger the age, the worse the adherence $(P<0 \cdot 001)$. Smoking habit and sedentary lifestyle had a positive relationship with low adherence. Women smoking $>20$ cigarettes/d showed a low adherence to the Mediterranean diet 5.36 times more often than women who had never smoked, OR $=5.36$ $(95 \% 1.91,15.07)$. The frequency of low adherence was double for women with minimal physical activity, $\mathrm{OR}=2 \cdot 07(95 \% \mathrm{CI} 1 \cdot 34,3 \cdot 17)$. This relationship was also seen for middle adherence and sedentary lifestyle. BMI was not associated with adherence to the Mediterranean diet in either the crude or the adjusted analysis. Factors associated with middle adherence were similar, although the force of association was minor in both the crude and adjusted analyses. 
Table 1 Mediterranean Diet Adherence Index score ${ }^{(35)}$ and total energy intake before pregnancy among healthy Spanish women $(n 1175)$, Virgen de las Nieves University Hospital of Granada, southern Spain, June 2004 to March 2007

\begin{tabular}{|c|c|c|c|c|c|c|c|c|c|c|c|c|c|}
\hline & \multirow[b]{2}{*}{$n$} & \multicolumn{6}{|c|}{ Mediterranean diet index score (points) } & \multicolumn{6}{|c|}{ Total energy intake $(\mathrm{kJ} / \mathrm{d})$} \\
\hline & & Mean & SD & Median & Minimum & Maximum & $P$ & Mean & SD & Median & Minimum & Maximum & $P$ \\
\hline Age (years) & & & & & & & 0.000 & & & & & & 0.000 \\
\hline$\geq 40$ & 17 & $30 \cdot 4$ & $2 \cdot 2$ & 31 & 24 & 33 & & 9853 & 2684 & 9294 & 6488 & 15345 & \\
\hline $35-39$ & 199 & $29 \cdot 4$ & $3 \cdot 0$ & 29 & 21 & 36 & & 9618 & 2584 & 9333 & 4746 & 19696 & \\
\hline $30-34$ & 436 & $28 \cdot 4$ & $3 \cdot 1$ & 28 & 20 & 36 & & 9610 & 2681 & 9257 & 3869 & 20418 & \\
\hline $25-29$ & 345 & $28 \cdot 7$ & $3 \cdot 1$ & 28 & 20 & 36 & & 10185 & 2971 & 9752 & 4320 & 19971 & \\
\hline$<25$ & 178 & $27 \cdot 0$ & $2 \cdot 9$ & 27 & 21 & 36 & & 11474 & 3397 & 10994 & 5606 & 19837 & \\
\hline Smoking & & & & & & & 0.000 & & & & & & 0.007 \\
\hline$>20$ cigarettes $/ d$ & 31 & $26 \cdot 3$ & $3 \cdot 0$ & 26 & 22 & 34 & & 10818 & 3484 & 10166 & 5768 & 19837 & \\
\hline$\leq 20$ cigarettes/d & 398 & $27 \cdot 6$ & 3.0 & 28 & 20 & 36 & & 10377 & 3164 & 9824 & 3869 & 19808 & \\
\hline 0 cigarettes $/ \mathrm{d}$ & 746 & $28 \cdot 6$ & $3 \cdot 2$ & 29 & 20 & 36 & & 9868 & 2768 & 9454 & 4115 & 20418 & \\
\hline Physical activity & & & & & & & 0.000 & & & & & & 0.927 \\
\hline Tertile 1 & 373 & $27 \cdot 8$ & $3 \cdot 1$ & 28 & 20 & 36 & & 10036 & 3008 & 9541 & 4320 & 19837 & \\
\hline Tertile 2 & 405 & $27 \cdot 9$ & $3 \cdot 1$ & 28 & 21 & 36 & & 10048 & 2796 & 9635 & 4115 & 19971 & \\
\hline Tertile 3 & 397 & $28 \cdot 9$ & $3 \cdot 2$ & 29 & 20 & 36 & & 10112 & 3018 & 9599 & 3869 & 20418 & \\
\hline Academic level & & & & & & & 0.000 & & & & & & 0.000 \\
\hline Primary & 478 & $27 \cdot 7$ & $3 \cdot 1$ & 28 & 20 & 36 & & 10829 & 3081 & 10443 & 4200 & 19971 & \\
\hline Secondary & 339 & $28 \cdot 2$ & $3 \cdot 1$ & 28 & 20 & 36 & & 9803 & 2603 & 9444 & 4465 & 20418 & \\
\hline University & 358 & $28 \cdot 8$ & $3 \cdot 1$ & 29 & 20 & 36 & & 9295 & 2800 & 8930 & 3869 & 19696 & \\
\hline BMI & & & & & & & 0.207 & & & & & & 0.619 \\
\hline Normal weight & 789 & $28 \cdot 1$ & $3 \cdot 1$ & 28 & 21 & 36 & & 10092 & 2995 & 9612 & 3869 & 20418 & \\
\hline Overweight & 268 & $28 \cdot 5$ & $3 \cdot 3$ & 29 & 20 & 36 & & 10099 & 2862 & 9537 & 4746 & 19808 & \\
\hline Obese & 118 & $27 \cdot 9$ & $3 \cdot 2$ & 28 & 20 & 36 & & 9815 & 2725 & 9562 & 4635 & 17879 & \\
\hline Social class & & & & & & & 0.000 & & & & & & 0.000 \\
\hline Class I & 172 & 28.5 & $3 \cdot 1$ & 28 & 20 & 36 & & 9206 & 2722 & 8835 & 3869 & 19685 & \\
\hline Class II & 144 & $29 \cdot 0$ & $3 \cdot 2$ & 29 & 20 & 36 & & 9657 & 2667 & 9100 & 4200 & 13272 & \\
\hline Class III & 346 & $28 \cdot 3$ & $3 \cdot 0$ & 28 & 21 & 36 & & 9706 & 2728 & 9404 & 4465 & 19837 & \\
\hline Class IV & 496 & $27 \cdot 8$ & $3 \cdot 2$ & 28 & 20 & 36 & & 10702 & 3082 & 10280 & 4707 & 20419 & \\
\hline Class V & 17 & $27 \cdot 9$ & $2 \cdot 6$ & 27 & 24 & 33 & & 10980 & 3213 & 9993 & 5560 & 18293 & \\
\hline Previous pregnancies & & & & & & & 0.000 & & & & & & $0 \cdot 161$ \\
\hline 0 & 555 & $27 \cdot 8$ & $3 \cdot 1$ & 28 & 20 & 36 & & 10028 & 3033 & 9547 & 3869 & 19837 & \\
\hline 1 & 365 & $28 \cdot 5$ & $3 \cdot 3$ & 29 & 20 & 36 & & 9891 & 2710 & 9514 & 4115 & 20418 & \\
\hline 2 & 168 & $28 \cdot 4$ & $3 \cdot 0$ & 29 & 21 & 35 & & 10228 & 3027 & 9665 & 4882 & 19971 & \\
\hline 3 & 61 & $29 \cdot 3$ & $2 \cdot 8$ & 29 & 23 & 36 & & 10611 & 3042 & 10093 & 5305 & 17469 & \\
\hline$\geq 4$ & 26 & $28 \cdot 8$ & $2 \cdot 6$ & 29 & 25 & 34 & & 10990 & 2948 & 10195 & 5576 & 17614 & \\
\hline Miscarriage & & & & & & & 0.006 & & & & & & 0.486 \\
\hline 0 & 933 & $28 \cdot 0$ & $3 \cdot 1$ & 28 & 20 & 36 & & 10015 & 2901 & 9548 & 3869 & 20418 & \\
\hline 1 & 199 & $28 \cdot 7$ & $3 \cdot 3$ & 29 & 20 & 36 & & 10234 & 3162 & 9634 & 4732 & 19971 & \\
\hline$\geq 2$ & 43 & $29 \cdot 1$ & $2 \cdot 9$ & 29 & 23 & 36 & & 10387 & 2660 & 10017 & 5305 & 17615 & \\
\hline Total & 1175 & $28 \cdot 2$ & $3 \cdot 2$ & 28 & 20 & 36 & & 10066 & 2937 & 9577 & 3869 & 20418 & \\
\hline
\end{tabular}

\section{Discussion}

Our results show that Mediterranean diet adherence was poor among childbearing women in the northern part of the province of Granada, Spain. Low Mediterranean diet adherence was more frequent in younger women, and it was associated with unhealthy practices such as smoking or physical inactivity, as well as with other possible determinants of health such as social class and educational level.

To our knowledge, the present study is the first one performed in Spain to assess the factors associated with adherence to the Mediterranean diet in healthy young women using the index developed by Serra-Majem et $a{ }^{(35)}$. While the benefits of good adherence to the Mediterranean diet are well known in the general population, it is important to stress its importance among healthy women of childbearing age ${ }^{(3-19,41,42)}$.

Although we worked with Spanish childbearing women, our results for the Mediterranean dietary pattern are in line with those of observational studies in populations of different characteristics or for other healthy dietary patterns in Spain ${ }^{(3,35,43-49)}$ and Europe ${ }^{(50)}$. We found a marked protector effect for age: as age increased, the probability of Mediterranean diet adherence increased. Dietary habits among healthy childbearing women are worsening, mainly among younger women. In Spain, consumption of fat, red meat, eggs and dairy products is on the rise, while intakes of cereals, vegetables, pulses, fruits and seafood have decreased, especially in the younger population. Andalusia is no exception to the trend affecting most developed countries.

Sedentary lifestyle ${ }^{(47,48)}$, smoking habit ${ }^{(47,48,50)}$, low educational level and social class ${ }^{(3,42,51,52)}$ and low adherence to the Mediterranean diet are factors that often accompany unhealthy lifestyles. The positive association we detected between physical activity and Mediterranean diet adherence is noteworthy in this context, suggesting that public health or preventive interventions must 


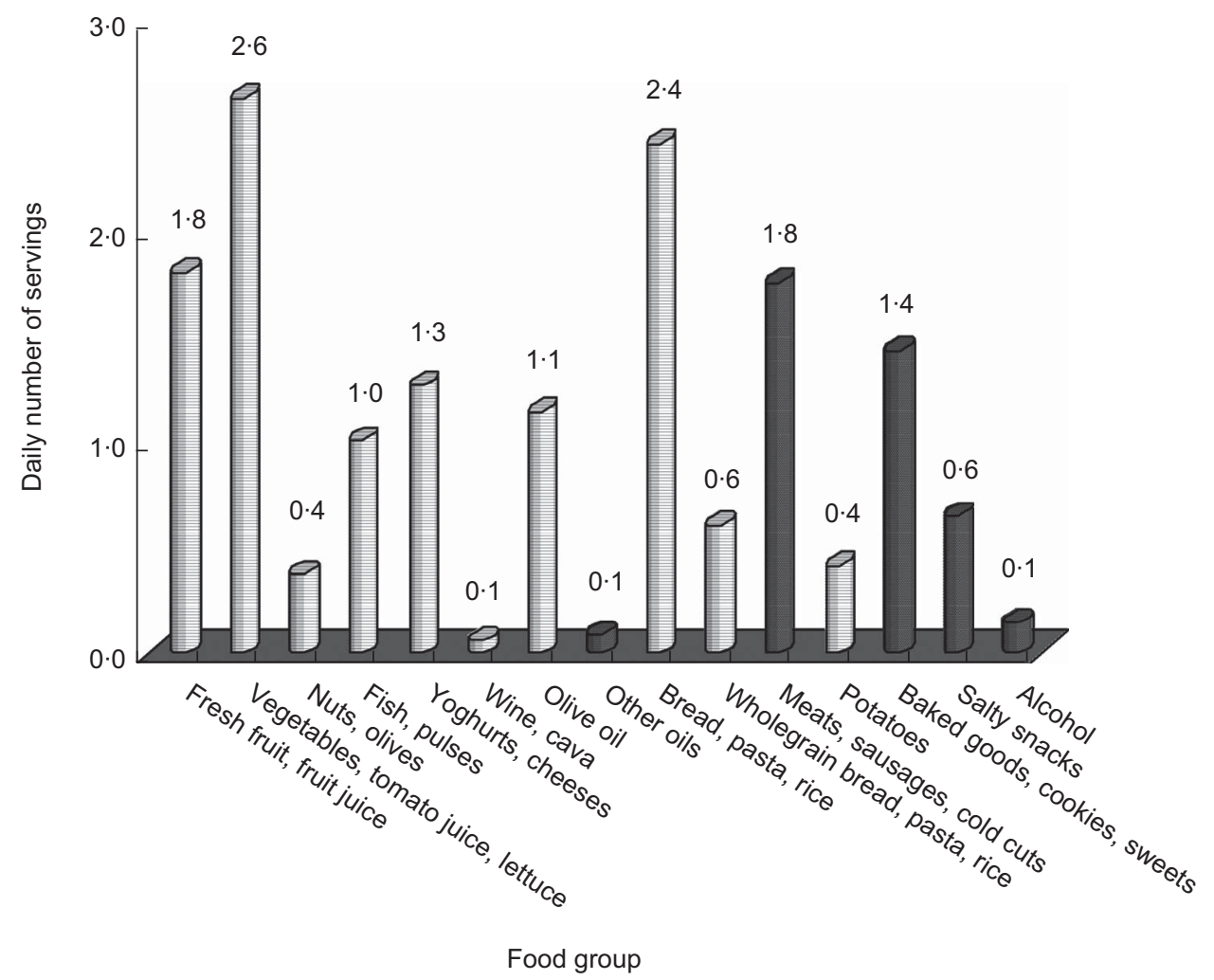

Fig. 1 Average daily number of servings of food groups (圆, healthy food groups; $\square$, unhealthy food groups) of the Mediterranean Diet Adherence Index ${ }^{(35)}$ before pregnancy among healthy Spanish women $(n 1175)$, Virgen de las Nieves University Hospital of Granada, southern Spain, June 2004 to March 2007

address diet and physical activity in conjunction. Poor diet and sedentary lifestyle have been identified as the main risk factors for obesity and chronic diseases, the greatest health problems in our population ${ }^{(53,54)}$. Likewise, a number of previous studies show an association between smoking and unhealthy dietary pattern ${ }^{(47,48,50)}$, highlighting lower fruit and fresh vegetable intake.

We found no association between obesity and quality of the diet. Other authors underline this lack of association $^{(55,56)}$, but in general it is assumed that the Mediterranean diet is associated with a lesser frequency of obesity ${ }^{(4,6)}$. This may be because trends in the overall population do not always appear at the individual level, as is the case in the association between diet and cholesterol levels ${ }^{(57)}$, or there may be an information bias in the sense that overweight is associated with underreporting of food intake. Such a bias is likely to be accentuated regarding unhealthy food intake, and must be acknowledged in view of our study design.

Finally, the association between lower socio-economic level, low adherence to a healthy diet and lower level of education (primary, secondary) supports previous findings: poor dietary habits, sedentary lifestyle and smoking are more common in lower socio-economic strata, reflecting considerable inequalities in the distribution of health determinants ${ }^{(3,58,59)}$.
As potential limitations of our study we should cite its observational nature, with dietary information recorded retrospectively (diet during the year previous to pregnancy self-reported at the 21 st week of gestation). This would entail some memory bias, possibly strengthened by the social desirability of avoiding substantial intake of unhealthy foodstuffs. Such a bias would be differential, mostly affecting women with poor dietary habits, decreasing the variability of the sample and the probability of obtaining significant associations. On the other hand, we acknowledge that some confounding variables considered could be measured imperfectly and the likelihood of residual confounding cannot be ruled out. As advantages of our study we should underline that: (i) our sample is representative of all healthy women in the reference area of Virgen de las Nieves University Hospital (southern Spain), meaning that the results can be extrapolated to a greater population; (ii) questionnaires previously validated in Spanish populations were used to measure the physical activity ${ }^{(37)}$ and food frequency ${ }^{(30)}$; and (iii) trained interviewers collected the information. We opted to use a dietary quality index as a dependent variable for our study because we think it summarizes the quality of the diet better ${ }^{(27)}$. Our understanding is that nutrition is derived from combinations of food and elements that interact ${ }^{(45-47)}$, and there is growing interest 
Table 2 Sample description for each level of adherence to the Mediterranean diet before pregnancy among healthy Spanish women ( $n$ 1175), Virgen de las Nieves University Hospital of Granada, southern Spain, June 2004 to March 2007

\begin{tabular}{|c|c|c|c|c|c|c|c|c|}
\hline & \multicolumn{2}{|c|}{$\begin{array}{l}\text { High adherence } \\
\quad(n \text { 397) }\end{array}$} & \multicolumn{2}{|c|}{$\begin{array}{l}\text { Middle adherence } \\
\qquad(n \text { 476) }\end{array}$} & \multicolumn{2}{|c|}{$\begin{array}{l}\text { Low adherence } \\
\qquad(n \text { 302) }\end{array}$} & \multicolumn{2}{|c|}{$\begin{array}{c}\text { Total } \\
(n 1175)\end{array}$} \\
\hline & $n$ & $\%$ & $n$ & $\%$ & $n$ & $\%$ & $n$ & $\%$ \\
\hline \multicolumn{9}{|l|}{ Age $\left(\right.$ years) ${ }^{* \star \star} t$} \\
\hline$<25$ & 23 & $12 \cdot 9$ & 69 & $38 \cdot 8$ & 86 & $48 \cdot 3$ & 178 & 100 \\
\hline $25-29$ & 98 & $28 \cdot 4$ & 151 & $43 \cdot 8$ & 96 & $27 \cdot 8$ & 345 & 100 \\
\hline $30-34$ & 164 & $37 \cdot 6$ & 185 & $42 \cdot 4$ & 87 & $20 \cdot 0$ & 436 & 100 \\
\hline $35-39$ & 100 & $50 \cdot 3$ & 68 & $34 \cdot 2$ & 31 & $15 \cdot 6$ & 199 & 100 \\
\hline$\geq 40$ & 12 & $70 \cdot 6$ & 3 & $17 \cdot 6$ & 2 & $11 \cdot 8$ & 17 & 100 \\
\hline \multicolumn{9}{|l|}{ Smoking ${ }^{\star * *}$} \\
\hline 0 cigarettes/d & 290 & 38.9 & 294 & $39 \cdot 4$ & 162 & 21.7 & 746 & 100 \\
\hline$\leq 20$ cigarettes $/ \mathrm{d}$ & 101 & $25 \cdot 4$ & 175 & $44 \cdot 0$ & 122 & $30 \cdot 7$ & 398 & 100 \\
\hline$>20$ cigarettes $/ \mathrm{d}$ & 6 & $19 \cdot 4$ & 7 & $22 \cdot 6$ & 18 & $58 \cdot 1$ & 31 & 100 \\
\hline \multicolumn{9}{|c|}{ Physical activity $(\mathrm{MET}-\mathrm{h} / \mathrm{d})^{\star \star *}$} \\
\hline Tertile $1(\leq 0.57)$ & 97 & $26 \cdot 0$ & 169 & $45 \cdot 3$ & 107 & $28 \cdot 7$ & 373 & 100 \\
\hline Tertile $2(0 \cdot 58-2 \cdot 19)$ & 132 & $32 \cdot 6$ & 150 & $37 \cdot 0$ & 123 & $30 \cdot 4$ & 405 & 100 \\
\hline Tertile $3(\geq 2 \cdot 20)$ & 168 & $42 \cdot 3$ & 157 & $39 \cdot 5$ & 72 & $18 \cdot 1$ & 397 & 100 \\
\hline \multicolumn{9}{|l|}{ Academic level ${ }^{\star \star \star}$} \\
\hline University & 175 & $48 \cdot 9$ & 135 & $37 \cdot 7$ & 48 & $13 \cdot 4$ & 358 & 100 \\
\hline Secondary & 108 & 31.9 & 148 & $43 \cdot 7$ & 83 & $24 \cdot 5$ & 339 & 100 \\
\hline Primary & 114 & $23 \cdot 8$ & 193 & $40 \cdot 4$ & 171 & $35 \cdot 8$ & 478 & 100 \\
\hline \multicolumn{9}{|l|}{$\mathrm{BMI}$} \\
\hline Normal weight & 264 & 33.5 & 321 & $40 \cdot 7$ & 204 & $25 \cdot 9$ & 789 & 100 \\
\hline Overweight & 96 & $35 \cdot 8$ & 109 & $40 \cdot 7$ & 63 & $23 \cdot 5$ & 268 & 100 \\
\hline Obese & 37 & $31 \cdot 4$ & 46 & $39 \cdot 0$ & 35 & $29 \cdot 7$ & 118 & 100 \\
\hline \multicolumn{9}{|l|}{ Social class $* * *$} \\
\hline Class I & 85 & $49 \cdot 4$ & 70 & $40 \cdot 7$ & 17 & $9 \cdot 9$ & 172 & 100 \\
\hline Class II & 61 & $42 \cdot 8$ & 60 & $41 \cdot 7$ & 23 & $16 \cdot 0$ & 144 & 100 \\
\hline Class III & 124 & $35 \cdot 8$ & 133 & $38 \cdot 4$ & 89 & $25 \cdot 7$ & 346 & 100 \\
\hline Class IV & 125 & $25 \cdot 2$ & 204 & $41 \cdot 1$ & 167 & $33 \cdot 7$ & 496 & 100 \\
\hline Class V & 2 & $11 \cdot 8$ & 9 & $52 \cdot 9$ & 6 & $35 \cdot 3$ & 17 & 100 \\
\hline \multicolumn{9}{|l|}{ Previous pregnancies } \\
\hline 0 & 168 & $30 \cdot 3$ & 236 & $42 \cdot 5$ & 151 & $27 \cdot 2$ & 555 & 100 \\
\hline 1 & 141 & $38 \cdot 6$ & 134 & $36 \cdot 7$ & 90 & $24 \cdot 7$ & 365 & 100 \\
\hline 2 & 56 & $33 \cdot 3$ & 70 & $41 \cdot 7$ & 42 & $25 \cdot 0$ & 168 & 100 \\
\hline 3 & 25 & $41 \cdot 0$ & 24 & $39 \cdot 3$ & 12 & $19 \cdot 7$ & 61 & 100 \\
\hline$\geq 4$ & 7 & 26.9 & 12 & $46 \cdot 2$ & 7 & $26 \cdot 9$ & 26 & 100 \\
\hline \multicolumn{9}{|l|}{ Miscarriage } \\
\hline 0 & 303 & 32.5 & 385 & $41 \cdot 3$ & 245 & $26 \cdot 3$ & 933 & 100 \\
\hline 1 & 78 & $39 \cdot 2$ & 72 & $36 \cdot 2$ & 49 & $29 \cdot 6$ & 199 & 100 \\
\hline$\geq 2$ & 16 & $37 \cdot 2$ & 19 & $44 \cdot 2$ & 8 & 18.6 & 43 & 100 \\
\hline
\end{tabular}

MET, metabolic equivalent of task.

Differences between low, middle and high adherence groups were significant: ${ }^{\star \star \star} P<0.001$.

tMinimum age 18 years, maximum age 45 years, arithmetic mean age $29 \cdot 81$ (sD $5 \cdot 14$ ) years.

in using dietary quality indices to evaluate whether adherence to a certain dietary pattern lowers the risk of disease.

On the other hand, the Mediterranean Diet Adherence Index used ${ }^{(35)}$ is dependent on the mean intake of people in the sample, which impedes comparison with other populations. That is, women in the lower Mediterranean diet adherence tertile may show better Mediterranean diet adherence than other populations. Notwithstanding, dietary pattern must be appraised in a cultural context, planning health-care interventions in view of the population, tradition and the availability of certain foods.

The prevalence of sedentary lifestyle and low adherence to the Mediterranean diet in our study population was high, in particular in younger women. This suggests that Mediterranean diet adherence could be decreasing. Our results urge that measures be taken to promote healthier lifestyles and that physical activity and nutritional education should be key components of maternal and child health-care programmes. In our particular setting, Andalusia, recommendations should be set forth to enhance awareness of healthy diet and lifestyle among childbearing women within the framework of a regional nutrition and health policy. Knowledge of the factors associated with low adherence to a Mediterranean diet is crucial for the design and implementation of health promotion and prevention programmes to improve the health status of the population in general, and childbearing women in particular. Modifying dietary habits is a socially and politically difficult task, calling for structural and individual interventions ${ }^{(35)}$.

Childbearing women could be an excellent target group for intervention; such preventive action would have a dual effect, present and future, meaning better 
Table 3 Factors associated with low and middle adherence to the Mediterranean diet before pregnancy among healthy Spanish women ( $n$ 1175), Virgen de las Nieves University Hospital of Granada, southern Spain, June 2004 to March 2007

\begin{tabular}{|c|c|c|c|c|c|c|c|c|}
\hline & \multicolumn{4}{|c|}{ Low adherencet } & \multicolumn{4}{|c|}{ Middle adherencet } \\
\hline & Crude OR & $95 \% \mathrm{Cl}$ & Adjusted OR $\ddagger$ & $95 \% \mathrm{Cl}$ & Crude OR & $95 \% \mathrm{Cl}$ & Adjusted OR & $95 \% \mathrm{Cl}$ \\
\hline \multicolumn{9}{|l|}{ Age (years) } \\
\hline$<25$ & \multicolumn{2}{|c|}{ Reference } & \multicolumn{2}{|c|}{ Reference } & \multicolumn{2}{|c|}{ Reference } & \multicolumn{2}{|c|}{ Reference } \\
\hline $25-29$ & $0 \cdot 26^{*}$ & $0.15,0.44$ & $0.44^{*}$ & $0.24,0.78$ & $0.51^{*}$ & $0.30,0.87$ & 0.68 & $0 \cdot 39,1 \cdot 19$ \\
\hline $30-34$ & $0 \cdot 14^{*}$ & $0.08,0.24$ & $0 \cdot 31^{*}$ & $0.17,0.56$ & $0 \cdot 37^{*}$ & $0.22,0.63$ & 0.58 & $0.33,1.02$ \\
\hline $35-39$ & $0.08^{*}$ & $0 \cdot 04,0 \cdot 15$ & $0 \cdot 16^{*}$ & $0.08,0.32$ & $0.22^{*}$ & $0 \cdot 12,0 \cdot 39$ & $0.33^{*}$ & $0.18,0.61$ \\
\hline$\geq 40$ & $0.04^{*}$ & $0.00,0.21$ & $0 \cdot 11^{*}$ & $0.02,0.59$ & $0 \cdot 08^{*}$ & $0.02,0.32$ & $0 \cdot 14^{\star}$ & $0.03,0.58$ \\
\hline \multicolumn{9}{|l|}{ Smoking } \\
\hline 0 cigarettes/d & \multicolumn{2}{|c|}{ Reference } & \multicolumn{2}{|c|}{ Reference } & \multicolumn{2}{|c|}{ Reference } & \multicolumn{2}{|c|}{ Reference } \\
\hline$\leq 20$ cigarettes $/ \mathrm{d}$ & $2 \cdot 16^{\star}$ & $1 \cdot 56,2 \cdot 99$ & $1 \cdot 62^{*}$ & $1 \cdot 13,2 \cdot 31$ & $1 \cdot 70^{*}$ & $1 \cdot 27,2 \cdot 29$ & $1 \cdot 48^{\star}$ & $1 \cdot 08,2 \cdot 02$ \\
\hline$>20$ cigarettes $/ d$ & $5 \cdot 37^{*}$ & $2 \cdot 09,13 \cdot 79$ & $5 \cdot 36^{\star}$ & $1 \cdot 91,15 \cdot 07$ & $1 \cdot 15$ & $0.38,3 \cdot 46$ & $1 \cdot 13$ & $0.36,3.58$ \\
\hline \multicolumn{9}{|c|}{ Physical activity (MET-h/d) } \\
\hline Tertile 3 & \multicolumn{2}{|c|}{ Reference } & \multicolumn{2}{|c|}{ Reference } & \multicolumn{2}{|c|}{ Reference } & \multicolumn{2}{|c|}{ Reference } \\
\hline Tertile 2 & $2 \cdot 17^{\star}$ & $1 \cdot 50,3 \cdot 14$ & $2 \cdot 29^{\star}$ & $1 \cdot 53,3 \cdot 44$ & $1 \cdot 21$ & $0.88,1.67$ & $1 \cdot 21$ & $0.87,1.69$ \\
\hline Tertile 1 & $2 \cdot 57^{*}$ & $1 \cdot 74,3 \cdot 80$ & $2 \cdot 07^{*}$ & $1 \cdot 34,3 \cdot 17$ & $1 \cdot 86^{*}$ & $1 \cdot 33,2 \cdot 59$ & $1 \cdot 64^{*}$ & $1 \cdot 16,2 \cdot 32$ \\
\hline \multicolumn{9}{|l|}{ Academic level } \\
\hline University & \multicolumn{2}{|c|}{ Reference } & \multicolumn{2}{|c|}{ Reference } & \multicolumn{2}{|c|}{ Reference } & \multicolumn{2}{|c|}{ Reference } \\
\hline Secondary & $2 \cdot 80^{*}$ & $1 \cdot 82,4 \cdot 30$ & $1 \cdot 59$ & $0.97,2 \cdot 61$ & $1 \cdot 77^{\star}$ & $1 \cdot 27,2 \cdot 48$ & $1 \cdot 49^{\star}$ & $1 \cdot 01,2 \cdot 19$ \\
\hline Primary & $5 \cdot 46^{*}$ & $3 \cdot 67,8 \cdot 13$ & $2 \cdot 18^{*}$ & $1 \cdot 30,3 \cdot 65$ & $2 \cdot 19^{*}$ & $1.59,3.03$ & $1 \cdot 48$ & $0.97,2 \cdot 25$ \\
\hline \multicolumn{9}{|l|}{ BMI } \\
\hline Obese & \multicolumn{2}{|c|}{ Reference } & \multicolumn{2}{|c|}{ Reference } & \multicolumn{2}{|c|}{ Reference } & \multicolumn{2}{|c|}{ Reference } \\
\hline Overweight & 0.69 & $0 \cdot 39,1 \cdot 21$ & $0 \cdot 67$ & $0 \cdot 36,1 \cdot 24$ & 0.91 & $0.54,1.52$ & 0.94 & $0.55,1.61$ \\
\hline Normal weight & 0.81 & $0 \cdot 49,1 \cdot 34$ & 1.00 & $0.58,1.72$ & 0.97 & $0.61,1.55$ & $1 \cdot 10$ & $0.67,1.79$ \\
\hline \multicolumn{9}{|l|}{ Social class } \\
\hline Class V & \multicolumn{2}{|c|}{ Reference } & Refer & ence & Refe & rence & Refere & nce \\
\hline Class IV & 0.44 & $0 \cdot 08,2 \cdot 24$ & $0 \cdot 41$ & $0 \cdot 07,2 \cdot 18$ & $0 \cdot 36$ & $0 \cdot 07,1 \cdot 70$ & 0.34 & $0.07,1.63$ \\
\hline Class III & 0.23 & $0.04,7 \cdot 74$ & 0.39 & $0 \cdot 07,2 \cdot 13$ & 0.23 & $0.05,1 \cdot 12$ & 0.29 & $0.06,1.44$ \\
\hline Class II & $0 \cdot 12^{\star}$ & $0.02,0.66$ & 0.28 & $0.04,1 \cdot 63$ & $0 \cdot 21$ & $0.04,1.05$ & 0.31 & $0.06,1.58$ \\
\hline Class I & $0 \cdot 06^{\star}$ & $0.01,0.35$ & $0 \cdot 19$ & $0.03,1.14$ & $0 \cdot 18^{*}$ & $0.03,0.87$ & 0.33 & $0.06,1.69$ \\
\hline Energy intake§ & 0.99 & $0.97,1.01$ & $1 \cdot 06^{*}$ & $1.03,1.09$ & 0.99 & $0 \cdot 98,1 \cdot 01$ & $1 \cdot 03^{*}$ & $1 \cdot 01,1 \cdot 06$ \\
\hline
\end{tabular}

MET, metabolic equivalent of task.

Association was significant: ${ }^{\star} P<0.05$.

tReference category: high adherence to the Mediterranean diet.

$\ddagger$ Adjusted for age, smoking status, physical activity and academic level.

$\S$ Energy intake was introduced as a continuous variable. The OR indicates the increase for each $418 \mathrm{~kJ}(100 \mathrm{kcal})$ increment in daily energy intake.

health for the mother in future pregnancies and for her offspring. The childbearing years can thus be seen as an ideal time to introduce some stimulus to modify behaviour in a positive way, taking advantage of the motivational factor ${ }^{(25,60)}$. In conclusion, despite the wellknown benefits of the Mediterranean diet, certain factors are contributing to its demise. To design adequate interventions in the future, we must take into account that younger age, low social class, primary educational level and the presence of unhealthy lifestyles, including smoking and lack of physical activity, are associated with low adherence to the Mediterranean diet.

\section{Acknowledgements}

Sources of funding: This research was funded by FIS Scientific Research Project PI 03/1207 and Junta de Andalucía Excellence Project CTS 05/942. Ethics: Ethical approval was given to this study by the Ethics Committees of the University of Granada and Virgen de las Nieves University Hospital. Conflicts of interest: The authors have no conflict of interest to declare. Authors' contributions: R.O.-R.,
J.G.F and C.A.P collected the information, analysed the data and wrote the first draft of the manuscript. J.M.M. and A.B.-C. participated in the design of the study and critically reviewed the manuscript. J.J.J.-M. coordinated the study and is the main author responsible for the study design and drafting of the manuscript. All authors have seen and approved the content and contributed to the work. Acknowledgements: The authors thank Jean Sanders for improving the use of English in the manuscript.

\section{References}

1. Keys A, Menotti A, Aravanis C et al. (1984) The seven countries study: 2289 deaths in 15 years. Prev Med 13, 141-154.

2. Keys A, Menotti A, Karvonen MJ et al. (1986) The diet and 15-year death rate in the seven countries study. Am J Epidemiol 124, 903-915.

3. Gonzalez CA, Argilaga S, Agudo A et al. (2002) Sociodemographic differences in adherence to the Mediterranean dietary pattern in Spanish populations. Gac Sanit 16, 214-221.

4. Schroder H, Marrugat J, Vila J et al. (2004) Adherence to the traditional Mediterranean diet is inversely associated with body mass index and obesity in a Spanish population. J Nutr 134, 3355-3361. 
5. Dontas AS, Zerefos NS, Panagiotakos DB et al. (2007) Mediterranean diet and prevention of coronary heart disease in the elderly. Clin Interv Aging 2, 109-115.

6. Buckland G, Bach-Faig A \& Serra Majem L (2008) Efficacy of Mediterranean diet in preventing obesity. A review of the literature. Rev Esp Obes 6, 329-339.

7. Trichopoulou A, Costacou T, Bamia C et al. (2003) Adherence to a Mediterranean diet and survival in a Greek population. $N$ Engl J Med 348, 2599-2608.

8. Sofi F, Cesari F, Abbate R et al. (2008) Adherence to Mediterranean diet and health status: meta-analysis. $B M J$ 337, a1344.

9. Serra-Majem L, Trichopoulou A, Ngo de la Cruz J et al. (2004) Does the definition of the Mediterranean diet need to be updated? Public Health Nutr 7, 927-929.

10. Estruch R, Martinez-Gonzalez MA, Corella D et al. (2006) Effects of a Mediterranean-style diet on cardiovascular risk factors: a randomized trial. Ann Intern Med 145, 1-11.

11. Buckland G, Gonzalez CA, Agudo A et al. (2009) Adherence to the Mediterranean diet and risk of coronary heart disease in the Spanish EPIC Cohort Study. Am J Epidemiol 170, 1518-1529.

12. Serra-Majem L, Roman B \& Estruch R (2006) Scientific evidence of interventions using the Mediterranean diet: a systematic review. Nutr Rev 64, 2 Pt 2, S27-S47.

13. Martinez-Gonzalez MA, de la Fuente-Arrillaga C, NunezCordoba JM et al. (2008) Adherence to Mediterranean diet and risk of developing diabetes: prospective cohort study. BMJ 336, 1348-1351.

14. Esposito K, Maiorino MI, Ceriello A et al. (2010) Prevention and control of type 2 diabetes by Mediterranean diet: a systematic review. Diabetes Res Clin Pract 89, 97-102.

15. Salas-Salvado J, Bullo M, Babio N et al. (2011) Reduction in the incidence of type 2 diabetes with the Mediterranean diet: results of the PREDIMED-Reus nutrition intervention randomized trial. Diabetes Care 34, 14-19.

16. Benetou V, Trichopoulou A, Orfanos P et al. (2008) Conformity to traditional Mediterranean diet and cancer incidence: the Greek EPIC cohort. Br J Cancer 99, 191-195.

17. Roman B, Carta L, Martinez-Gonzalez MA et al. (2008) Effectiveness of the Mediterranean diet in the elderly. Clin Interv Aging 3, 97-109.

18. Verberne L, Bach-Faig A, Buckland G et al. (2010) Association between the Mediterranean diet and cancer risk: a review of observational studies. Nutr Cancer 62, 860-870.

19. Trichopoulou A, Lagiou P, Kuper H et al. (2000) Cancer and Mediterranean dietary traditions. Cancer Epidemiol Biomarkers Prev 9, 869-873.

20. Timmermans S, Steegers-Theunissen RP, Vujkovic M et al (2012) The Mediterranean diet and fetal size parameters: the Generation R Study. Br J Nutr 108, 1399-1409.

21. Carmichael SL, Yang W, Feldkamp ML et al. (2012) Reduced risks of neural tube defects and orofacial clefts with higher diet quality. Arch Pediatr Adolesc Med 166, 121-126.

22. Chatzi L, Mendez M, García R et al. (2012) Mediterranean diet adherence during pregnancy and fetal growth: INMA (Spain) and RHEA (Greece) mother-child cohort studies. Br J Nutr 107, 135-145.

23. da Silva R, Bach-Faig A, Raido Quintana B et al. (2009) Worldwide variation of adherence to the Mediterranean diet, in 1961-1965 and 2000-2003. Public Health Nutr 12, 1676-1684.

24. Galán I, Rodríguez-Artalejo F, Tobías A et al. (2005) Clustering of behavioural risk factors and their association with subjective health. Gac Sanit 19, 370-378.

25. Cuco G, Fernandez-Ballart J, Sala J et al. (2006) Dietary patterns and associated lifestyles in preconception, pregnancy and postpartum. Eur J Clin Nutr 60, 364-371.
26. Rayburn WF \& Phelan ST (2008) Promotion of healthy habits during pregnancy. Obstet Gynecol Clin North Am 35, 358-400.

27. Ortiz-Andrellucchi A, Sanchez-Villegas A, Ramirez-Garcia O et al. (2009) Assessment of nutritional quality in healthy pregnant women of the Canary Islands, Spain. Med Clin (Barc) 133, 615-621.

28. Phelan S (2010) Pregnancy: a 'teachable moment' for weight control and obesity prevention. Am J Obstet Gynecol 202, 135.e1-135.e8.

29. Servicio Andaluz de Salud, Hospital Materno Infantil Virgen de las Nieves (2011) Indicadores de Resultado. http://www.hvn.es/servicios_asistenciales/ginecologia_y_ obstetricia/estadistica_resultado.php (accessed February 2011).

30. Martín-Moreno JM, Boyle P, Gorgojo L et al. (1993) Development and validation of a food frequency questionnaire in Spain. Int J Epidemiol 22, 512-519.

31. Razquin C, Martinez JA, Martinez-Gonzalez MA et al. (2010) A 3-year Mediterranean-style dietary intervention may modulate the association between adiponectin gene variants and body weight change. Eur J Nutr 49, 311-319.

32. Marin C, Ramirez R, Delgado-Lista J et al. (2011) Mediterranean diet reduces endothelial damage and improves the regenerative capacity of endothelium. $A m \mathrm{~J}$ Clin Nutr 93, 267-274.

33. Beunza JJ, Toledo E, Hu FB et al. (2010) Adherence to the Mediterranean diet, long-term weight change, and incident overweight or obesity: the Seguimiento Universidad de Navarra (SUN) cohort. Am J Clin Nutr 92, 1484-1493.

34. Garaulet M, Hernandez-Morante JJ, Tebar FJ et al. (2011) Relation between degree of obesity and site-specific adipose tissue fatty acid composition in a Mediterranean population. Nutrition 27, 170-176.

35. Serra-Majem L, Ribas-Barba L, Salvador G et al. (2007) Compliance with dietary guidelines in the Catalan population: basis for a nutrition policy at the regional level (the PAAS strategy). Public Health Nutr 10, 1406-1414.

36. Willett W (1998) Nutritional Epidemiology, 2nd ed. New York: Oxford University Press.

37. Pereira MA, FitzerGerald SJ, Gregg EW et al. (1997) A collection of Physical Activity Questionnaires for healthrelated research. Med Sci Sports Exerc 29, 6 Suppl., S1-S205.

38. Ainsworth BE, Haskell WL, Whitt MC et al. (2000) Compendium of physical activities: an update of activity codes and MET intensities. Med Sci Sports Exerc 32, 9, Suppl., S498-S504.

39. Álvarez-Dardet C, Alonso J, Domingo A et al. (1995) Grupo de trabajo de la sociedad española de epidemiología. La medición de la clase social en ciencias de la salud (Working Group of the Spanish Society of Epidemiology. Measuring Social Class in Health Sciences), pp. 63-67. Barcelona: SG.

40. World Health Organization (2000) Obesity: Preventing and Managing the Global Epidemic. Report of a WHO Consultation. WHO Technical Report Series no. 894. Geneva: WHO.

41. Mariscal-Arcas M, Rivas A, Monteagudo C et al. (2009) Proposal of a Mediterranean diet index for pregnant women. Br J Nutr 102, 744-749.

42. Serra-Majem L, Bes-Rastrollo M, Roman-Vinas B et al. (2009) Dietary patterns and nutritional adequacy in a Mediterranean country. Br J Nutr 101, Suppl. 2, S21-S28.

43. Kourlaba G \& Panagiotakos DB (2009) Dietary quality indices and human health: a review. Maturitas 62, 1-8.

44. Milà-Villarroel R, Bach-Faig A, Puig J et al. (2011) Comparison and evaluation of the reliability of indexes of adherence to the Mediterranean diet. Public Health Nutr 14, 2338-2345.

45. Bach A, Serra-Majem L, Carrasco JL et al. (2006) The use of indexes evaluating the adherence to the Mediterranean diet in epidemiological studies: a review. Public Health Nutr 9, 132-146. 
46. Waijers PM, Feskens EJ \& Ocké MC (2007) A critical review of predefined diet quality scores. Br J Nutr 97, 219-231.

47. Sanchez-Villegas A, Martinez JA, De Irala J et al. (2002) Determinants of the adherence to an 'a priori' defined Mediterranean dietary pattern. Eur J Nutr 41, 249-257.

48. Moreno-Gómez C, Romaguera-Bosch D, Tauler-Riera P et al. (2012) Clustering of lifestyle factors in Spanish university students: the relationship between smoking, alcohol consumption, physical activity and diet quality. Public Health Nutr 15, 2131-2139.

49. Sánchez-Villegas A, Delgado-Rodríguez M, MartínezGonzález MA et al. (2003) Gender, age, socio-demographic and lifestyle factors associated with major dietary patterns in the Spanish Project SUN (Seguimiento Universidad de Navarra). Eur J Clin Nutr 57, 285-292.

50. Laaksonen M, Prattala R \& Karisto A (2001) Patterns of unhealthy behaviour in Finland. Eur J Public Health 11, 294-300.

51. Johansson L, Thelle DS, Solvoll K et al. (1999) Healthy dietary habits in relation to social determinants and lifestyle factors. Br J Nutr 81, 211-220.

52. Erkkila AT, Sarkkinen ES, Lehto S et al. (1999) Diet in relation to socioeconomic status in patients with coronary heart disease. Eur J Clin Nutr 53, 662-668.
53. Belahsen R \& Rguibi M (2006) Population health and Mediterranean diet in southern Mediterranean countries. Public Health Nutr 9, 1130-1135.

54. Ballesteros Arribas JM, Dal-Re Saavedra M, Pérez-Farinós N et al. (2007) The Spanish strategy for nutrition, physical activity and the prevention of obesity (NAOS Strategy). Rev Esp Salud Publica 81, 443-449.

55. Kontogianni MD, Melistas L, Yannakoulia M et al. (2009) Association between dietary patterns and indices of bone mass in a sample of Mediterranean women. Nutrition 25, 165-171.

56. Rossi M, Negri E, Bosetti C et al. (2008) Mediterranean diet in relation to body mass index and waist-to-hip ratio. Public Health Nutr 11, 214-217.

57. Pérez-Jiménez F, Ros E, Solá R et al. (2006) Tips to help control cholesterol with a healthy diet. Clin Invest Arterioscl 18, 104-110.

58. Power C \& Matthews S (1997) Origins of health inequalities in a national population sample. Lancet 350, 1584-1589.

59. Karlsdotter K, Martín Martín JJ \& López Del Amo González MP (2012) Multilevel analysis of income, income inequalities and health in Spain. Soc Sci Med 74, 1099-1106.

60. Benelam B (2011) Physical activity in pregnancy. Nutr Bull 36, 370-372. 